\title{
Talking about the Cultivation of Computer Professional Software Development
}

\section{Liang Wu}

Anyang Normal University, Anyang, Henan, 455000, china

\begin{abstract}
Software development ability is a necessary professional ability for computer majors. In the future, if you want to be competent in the computer industry, the job must have a foundation of software development. At present, in the teaching process of computer majors, there are many problems with software development teaching. For students' ability training, it has a great negative impact. This article studies the problems in the cultivation of computer professional software development ability, explores effective training measures, and promotes the improvement of the software development ability of students of this major.

Keywords: Computer; Software Development; Ability Training

The cultivation of software development ability has always been a very important content in the computer major. Students can only play their value in the industry if they truly master the software development ability. Faced with many shortcomings in the current computer software development teaching, adopt Traditional teaching methods are difficult to improve students' software development capabilities. In order to cultivate application-oriented software development technical talents and for the future development of the industry, these problems must be faced squarely and effective measures must be taken to solve them.
\end{abstract}

\section{The necessity of cultivating students' software development ability}

The computer as a whole is composed of basic hardware facilities and software. The software is an indispensable part of the computer in normal use, so this also laid the foundation for the importance of software development in computer majors, and the related software development in computer majors Knowledge runs through and is a very critical foundation for students' learning. It can be seen that cultivating students' software development capabilities will help students better master the use of computers. Therefore, software development should be regarded as an important part of the teaching objectives of computer science. component.

\section{Problems existing in the teaching of software development for computer majors}

Since information technology is the dominant force in current social development, major universities attach great importance to the cultivation of computer professionals. Therefore, as an important part of computer professional teaching, software development teaching has also received extensive attention. In fact, there are many deficiencies in software development teaching. Because of these deficiencies, students do not have sufficient knowledge of software development, and it is not good for the cultivation of software development capabilities. For example, even under the promotion of educational reforms, the teaching methods of software development teaching have not been innovated in accordance with the current situation. The traditional teaching mode is still used to find practical and practical

Copyright (C) 2020 Liang Wu

doi: $10.18282 /$ le.v9i7.1510

This is an open-access article distributed under the terms of the Creative Commons Attribution Non-Commercial License

(http://creativecommons.org/licenses/by-nc/4.0/), which permits unrestricted non-commercial use, distribution, and reproduction in any medium, provided the original work is properly cited. 
operation teaching. This is for stimulating students' creativity. The more difficult and boring theoretical courses will affect students' interest in computer learning. The lack of practical teaching makes it difficult for students to realize the role of computer learning. There is a serious disconnection from practical learning. More and more students start Give up studying. In addition, software development teaching has high requirements for students' divergent thinking and creative ability. However, in the actual teaching process, teaching cases are often based on imitation. This teaching method greatly limits students' creativity and limits The training of software development capabilities.

\section{Specific strategies for cultivating software development capabilities}

\subsection{Improve teachers' computer software development level}

Teachers are the leaders of students, and their level directly determines the quality of teaching. If you want to improve students' software development capabilities in teaching, teachers are required to master high-level software development skills and have rich software development experience. Software development teaching based on experience can make teachers' teaching more persuasive, and can also make teachers more meaningful, rather than just interpreting the text. At the same time, if the teacher's software development level is relatively high, it will become a model for students to learn from, provide the most accurate guidance for students' software development practice, efficiently solve the problems faced by students in practice, and enable students to have a deeper understanding of software development. Knowledge, a firmer grasp of software development skills.

\subsection{Stimulate students' interest in software development}

Under the trend of subjective initiative, students can be more engaged in learning, which should be conducive to the improvement of students' personal ability. The subjective initiative of students needs to be stimulated by interest, so teachers should use interest as the starting point to continuously optimize the teaching of software development courses. First, practice is the key to stimulating students' interest. Software development courses should be equipped with professional practice equipment to provide students with infrastructure support. Second, teachers should analyze students' psychology, find students' points of interest, and make students feel the joy of software development through project participation or competitions.

\subsection{Reasonable arrangement of teaching courses}

The rationality of curriculum arrangement is the basic guarantee of teaching quality. At present, many computer majors in colleges and universities have obvious problems in the arrangement of software development courses. This is mainly due to the lack of attention to software development courses in schools and adherence to traditional education in the teaching process. The learning model cannot be reformed and innovated. Therefore, in order to cultivate students' software development capabilities, colleges and universities must carry out management and control of teaching courses, starting from the teaching goals, and rationally arrange teaching courses.

\subsection{Strengthen practical teaching of software development}

It is difficult to improve software development ability in all directions only through written teaching. Therefore, practical teaching must be integrated into software development courses, and theoretical knowledge and practical ability can be effectively converted and integrated through practical training. Practical training is not just about letting students operate on the computer, teachers should also lead students to conduct comprehensive software development simulation training, so that students can truly invest in software development and creation, so as to improve students' creative ability and improve students' theoretical knowledge. Deepen, lay the foundation for its follow-up learning.

\section{Concluding remarks}

With the increasing maturity and wide application of information technology, computer software is also being continuously developed and popularized. The development of society puts forward diversified requirements for software development. Therefore, computer majors should also target social needs and formally teach software development. It is 
important to arrange software development courses reasonably, improve students' software development capabilities in teaching and practice, and train more high-quality professionals for the society.

\section{References}

1. Hu Shuai, Wang Hongjuan. On the cultivation of computer professional software development ability [J]. Computer Knowledge and Technology, 2020, 16(05): 63-64+86.

2. Wang Yuguo. Research on the Cultivation of Software Development Ability of Computer Science and Technology Students[J]. China Education Information, 2017(21): 83-85.

3. Wang Qi, Wang Chunhong. Research on the Construction of Computer Professional Software Development Course Group Oriented to Application Ability Training[J]. Computer Times, 2016(05): 84-86. 